\title{
Guar gum reduces the incidence of streptozotocin-induced renal tumors in Wistar rats
}

\author{
Beth C. Chin, Richard C. Renlund and Norman S. Track \\ Departments of Surgery, Clinical Biochemistry and Nutritional Sciences, University of Toronto and Mount Sinai \\ Hospital, Toronto, Ontario, Canada
}

\begin{abstract}
The effect of feeding guar gum or bran fibre diets upon the incidence of renal tumors was examined in streptozotocin diabetic rats. Guar gum fed rats gained significantly less weight during the first 14 weeks of the study than the bran fibre group. At 18 weeks, six rats from each group were sacrificed; two bran fibre rats had renal tumors. At the end of the study ( 42 weeks), significantly $(P<0.005)$ fewer renal tumors were found in the guar gum group $(12 \% ; 3 / 25)$ compared with the bran fibre group $(69 \% ; 25 / 36)$. This dramatic reduction of renal tumor incidence associated with guar gum consumption warrants further investigation.
\end{abstract}

\begin{abstract}
At present, there is a great deal of interest in the potential role of certain types of dietary fibre in maintaining or improving general health. Of specific interest are the claims that certain types of dietary fibre reduce carcinogenesis and improve carbohydrate/lipid metabolism. The anti-carcinogenesis interest comes from both epidemiological (3) and animal $(14,21)$ cancer studies which demonstrated reduced colon cancer in association with high intake of certain dietary fibre (e.g. wheat bran, citrus fibre). Most animal dietary fibre studies have concentrated upon intestinal cancer $(14,21)$; recently, a reduced incidence of spontaneous liver neoplasms was observed in fibre (konjac mannan) fed mice (10). In addition to potential anti-tumor effects, certain types of dietary fibre improve carbohydrate tolerance in both healthy and diabetic subjects $(5,7)$ and animals (19).

The present study was designed essentially to assess chronic effects of dietary fibre consumption upon metabolic parameters in streptozotocin-induced non-insulin dependent diabetic rats. These data will be the subject of a separate report. Streptozotocin also induces renal tumors $(1,8,12,13)$. Data on renal tumor incidence in streptozotocin-induced diabetic rats fed either an $8 \%$ guar gum or a $6 \%$ bran fibre standard rodent chow diet are presented in this report.
\end{abstract}

Male, Wistar rats (240-260 g, Woodlyn Farms, Guelph, Ontario) were housed individually and allowed free access to tap water and standard pelleted rodent chow (Diet No. 5001, Ralston Purina, St. Louis, MO). After a two week acclimatization period, rats were deprived of food overnight $(18 \mathrm{~h})$ and the following morning were injected intraperitoneally with $50 \mathrm{mg} / \mathrm{kg}$ streptozotocin (Sigma) to induce non-insulin dependent diabetes (6).

Twelve days later diabetic severity was assessed. Rats with plasma glucose levels exceeding $11 \mathrm{mmol} / 1$ following overnight food deprivation $(18 \mathrm{~h})$ were considered diabetic. Diabetic rats were ranked according to weight. Every second rat was placed in the guar gum group $(\mathrm{n}=58)$ and fed a pelleted $8 \%$ guar gum diet. The remaining rats $(n=60)$ formed the bran fibre group and were maintained on $6 \%$ bran fibre standard rodent chow diet. Diet components are listed in Table 1. The bran fibre diet is a commercial diet (No. 5001, Ralston Purina) formulated to achieve optimal growth in rodents (caloric percent: carbohydrate $60 \%$; protein $28 \%$; fat $12 \%$ ). The guar gum diet is a semi-synthetic diet designed to approximate the caloric distribution of a typical Western diet (carbohydrate 57\%; protein 17\%; fat $26 \%$ ). Rats were fed ad libitum, received no insulin therapy and were weighed weekly. 
Table 1 Ingredients of Guar Gum and Bran Fibre Diets

\begin{tabular}{llrlr}
\hline \multicolumn{1}{c}{ Test diet } & \multicolumn{2}{c}{ Guar gum } & \multicolumn{2}{c}{ Bran fibre** } \\
\hline Ingredients & Casein & $16.5 \%$ & Protein & $23.0 \%$ \\
& Methionine/choline & $0.5 \%$ & & \\
& Corn oil & $11.5 \%$ & Animal fat & $4.5 \%$ \\
& Dextrose/starch & $56.5 \%$ & Dextrose/starch & $49.0 \%$ \\
& Vitamins/minerals & $7.0 \%$ & Vitamins/minerals & $7.3 \%$ \\
& & & Moisture & $10.2 \%$ \\
& Guar gum* & $8.0 \%$ & Bran fibre & $6.0 \%$ \\
\hline Physiological fuel & & 3.95 & & 3.30 \\
value (kcal/g) & & & & \\
\hline
\end{tabular}

*Jaguar A-40-F, Celanese Polymer Specialties Co., Charlston, SC. **Diet No. 5001, Ralston Purina, St. Louis, MO

Table 2 Mean ( \pm SEM) Daily Food and Caloric Intake of Guar Gum Fed and Bran Fibre Fed Rats during the 11th and 41st Weeks of the Study

\begin{tabular}{lccccccc}
\hline \multirow{2}{*}{ Test group } & \multicolumn{3}{c}{ Week 11 } & & \multicolumn{3}{c}{ Week 41 } \\
\cline { 2 - 4 } \cline { 6 - 8 } & $\mathrm{n}$ & Food & Calories & & $\mathrm{n}$ & Food & Calories \\
\hline Guar gum & 9 & $39.0 \pm 1.9^{*}$ & $154.1 \pm 7.5^{*}$ & & 12 & $29.0 \pm 1.0$ & $114.6 \pm 3.9^{*}$ \\
Bran fibre & 9 & $54.5 \pm 2.7$ & $179.5 \pm 8.9$ & & 12 & $31.3 \pm 1.3$ & $103.3 \pm 4.3$ \\
\hline
\end{tabular}

* $P<0.05$ compared to control group

Following metabolic studies after 18 weeks on the test diets, six rats from each group were sacrificed and tissue samples of pancreas, lung, liver and kidney examined by routine histological techniques. The remaining animals were studied for another 24 weeks. Any moribund rat was sacrificed. Autopsies were performed on all animals sacrificed or found dead.

Plasma glucose concentrations were determined using a Beckman Glucose Analyzer 2. Data were analyzed using the Student's twotailed $t$-test for unpaired data and the chi-square test of association; probability values less than 0.05 were considered significant.

Two days prior to commencement of the study mean fasted body weights did not differ significantly between guar gum and bran fibre groups. During the first 14 weeks of the study, guar gum fed rats gained significantly less weight than bran fibre rats (Fig. 1). Similar mean body weights were maintained over the following 20 weeks; for the balance of the study the guar gum group weighed significantly more. Guar gum fed rats consumed significantly less food (and calories) during the 11th week (Table 2). By week 41, both groups had decreased significantly their food consumption compared to the 11th week
Table 3 Overall Incidence of Renal Pathology in Guar Gum and Bran Fibre Fed Rats

\begin{tabular}{lcc}
\hline Category & Guar gum & Bran fibre \\
\hline Healthy & 22 & 11 \\
Adenoma & 0 & 16 \\
Adenocarcinom & 1 & 9 \\
Sarcoma & 2 & 0 \\
\hline
\end{tabular}

(Table 2). Food intake between the two groups was not different at this time but caloric intake was marginally higher in the guar gum group.

Two of the six bran fibre rats sacrificed at 18 weeks had macroscopically visible renal tumors which were identifred as renal adenomas histologically. No renal pathology was detected in the six guar gum fed rats. All other tissues appeared normal. The overall incidence of renal pathology in the two groups is categorized in Table 3. Epithelial tumors (adenomas/adenocarcinomas) consisted of well differentiated, highly vascularized tubules originating from renal epithelium (Fig. 2), whereas the mesenchymal tumors (sarcomas) were composed of mesenchymal cells in a loose myxoid stroma which had resulted in compres- 


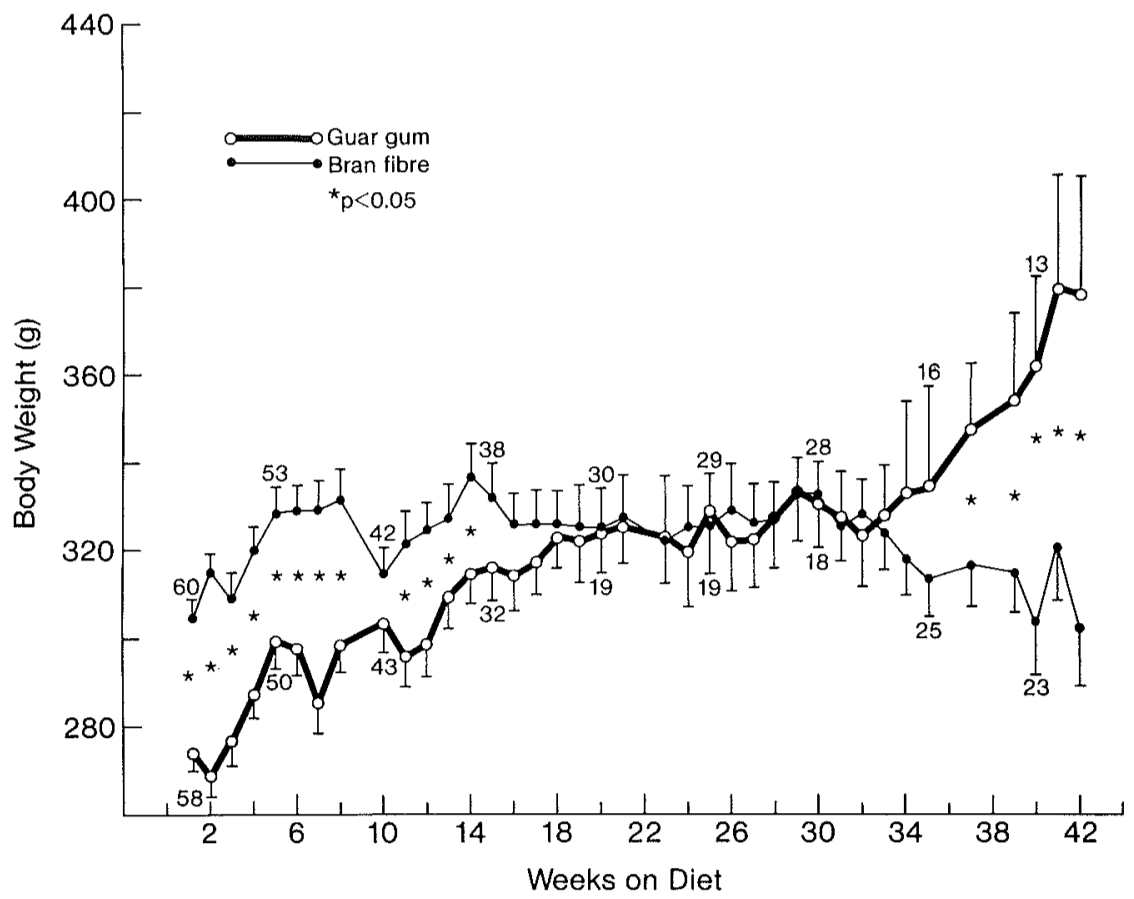

Fig. 1 Mean ( \pm SEM) body weight of streptozotocin diabetic rats fed guar gum or bran fibre diets. The number of rats surviving in each group is denoted every five weeks.

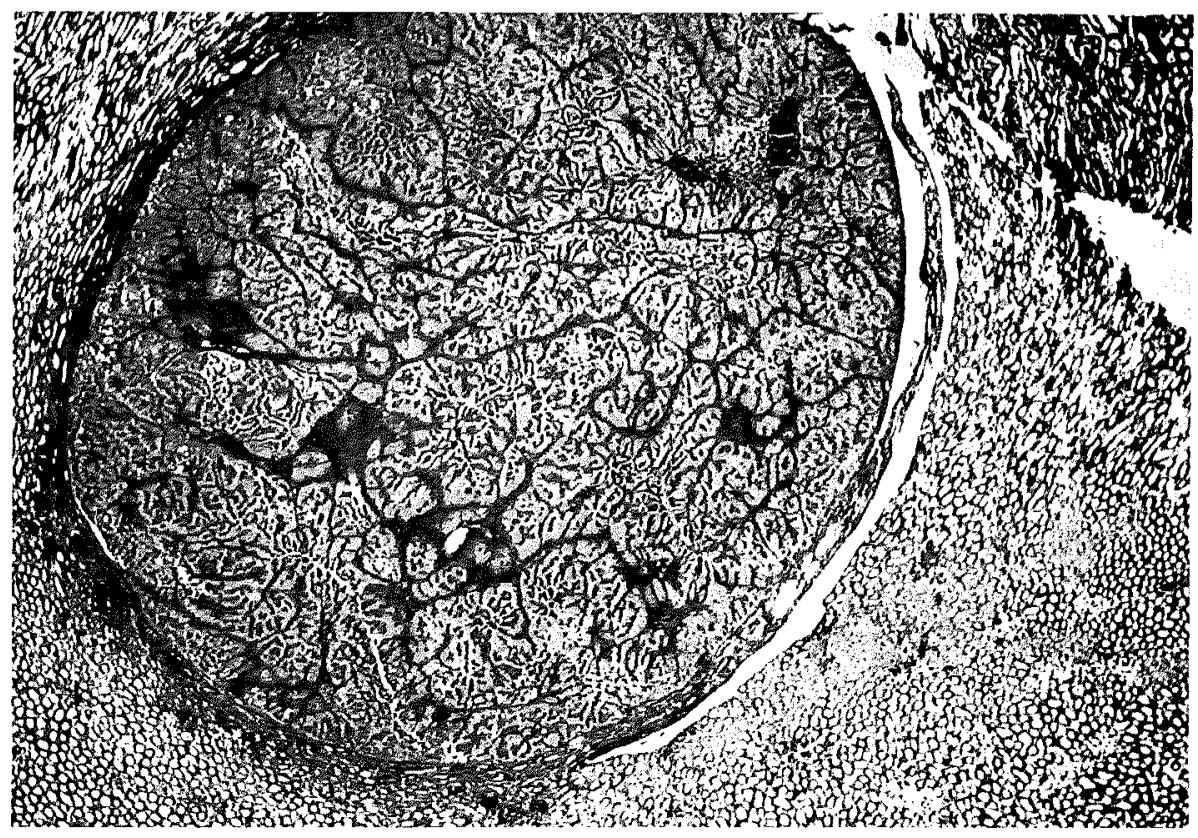

Fig. 2 Renal adenoma showing compression of adjacent renal parenchyma. $\times 22$ 


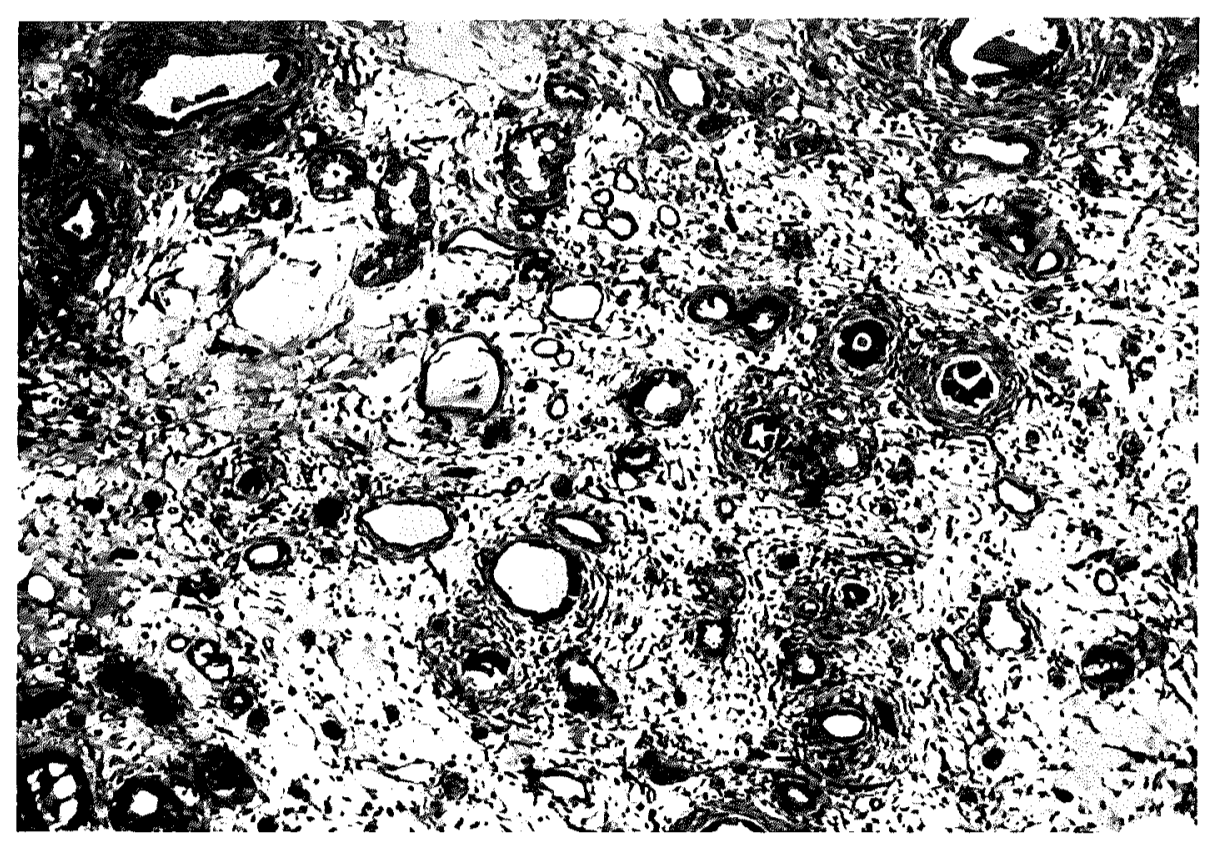

Fig. 3 Renal mesenchymal tumor showing spindle and stellate cells with clear cytoplasm. Several layers of these cells surround many sequestered tubules. $\times 100$

sion of renal tubules (Fig. 3). Later in the study, affected kidneys contained much larger and multiple tumors. Guar gum fed rats had significantly $(P<0.005)$ fewer tumors compared with the bran fibre group. Of all the rats examined, only one islet cell tumor (carcinoma) was observed and this was found in a bran fibre rat with normal kidneys.

This study suggests that a guar gum diet possesses the ability to reduce the incidence of streptozotocin-induced renal tumors in male Wistar rats. In other rat strains administered similar doses of streptozotocin reported incidences of renal tumors range from $25-77 \%(1,8,12,13)$. The tumor incidence of the guar gum group is surprisingly low and well below the lower end of this range while the incidence of the bran fibre group is well within the upper end of this range. In these other studies, rats consumed standard rodent diets similar to the bran fibre diet employed in this study.

A number of factors must be considered in attempting to explain the lower incidence of renal tumors in guar-fed rats. The two diets are definitely an important consideration. Reduced kidney disease is found in rats by decreasing carbohydrate intake, regardless of protein intake (2); therefore, it is unlikely that the very similar carbohydrate portions of the two diets influence renal tumorigenesis. When sufficient protein is provided to support normal growth, dietary protein has little effect upon tumor growth (18). Both diets provide more than sufficient protein (12\%) for normal growth (15). Dietary fat is implicated as a promoter of bowel, breast and prostrate cancer (4). If fat affects renal tumorigenesis, then the guar group would be at higher risk than the bran fibre group; no evidence suggests that fat influences renal tumorigenesis and the guar group had fewer rather than more tumors. Thus, available evidence of the effect of nutrition upon renal tumorigenesis suggests that the differences in the two diets are unlikely to be a major factor in the significantly reduced tumor incidence of the guar fed group.

Another factor is the reduced weight gain during the initial part of the study. It is well known that prolonged $(17,20)$ and even short-term (16) food restriction with concomitant reduced weight gain results in reduced tumor incidence. During the first 14 weeks of this study, the guar gum group exhibited a reduced weight gain. Even though both groups had free access to their diets, the guar gum group consumed significantly less food/calories at the beginning of the study. In other experiments performed in this laboratory, it was found that when healthy, male Wistar rats were fed isocaloric guar gum or cellu- 
lose diets their daily diet consumption was identical; however, the guar gum group exhibited reduced weight gain for the first 16-18 weeks of the study. This observation suggests that consuming guar gum alters the utilization of calories once in the digestive system.

A third factor is that a guar gum constituent affects promotion following tumor induction by streptozotocin. Support for this conjecture comes from two other reports in which a similar type of dietary fibre (konjac mannan) reduced the incidence of spontaneous liver tumors in mice (10) and dimethylhydrazine-induced colon tumors in rats (11). In the konjac mannan studies, both mice and rats consuming konjac mannan diets had reduced weight gain. In a major toxicological study of a number of food additives, some improvements in spontaneous tumor incidences were observed after chronic guar gum consumption (9); although positive effects were associated with reduced weight gain. In these three studies it is impossible to separate the influence of reduced weight gain from other potential anti-tumor factors.

One approach to examine the influence of reduced weight gain would be to include a foodrestricted bran fibre group to match the reduced weight gain of the guar gum group and determine if this manipulation can produce the same reduction in tumor incidence. The potential therapeutic importance of guar gum having an anti-cancer activity warrants the pursuance of this approach.

This work was supported in part by the Harold Tanenbaum Department of Research, Mount Sinai Hospital. The authors thank Carol Brotman, Margaret Cawkwell, Susan Chiu, Karen Gerry, Anthony Hayes, Sean Haberer, Al Higdon, Wally Nazarewycz and John Wallace for their assistance in performing this study.

Received for publication I February 1984

\section{REFERENCES}

1. ARIson R. N. and Feudale E. L. (1967) Induction of renal tumour by streptozotocin in rats. Nature 214, 1254-1255

2. Bras G. and Ross M. H. (1964) Kidney disease and nutrition in the rat. Toxicol. Appl. Pharmacol. 6, 247-262

3. Burkitt D. P. (1975) Large-bowel cancer: An epidemiologic jigsaw puzzle. J. Natl. Cancer Inst. 54, 3-6

4. Carroll K, K. (1983) The role of dietary fat in carcinogenesis. In Diets, Fats and Health (ed. Perkins E. G. and VISEK W. J.) American Oil Chemists' Society, Champaign, IL, pp. 710-720

5. Jenkins D. J. A., Leeds A. R., Gassull M. A.,
Cochet B. and Albertı K. G. M. M. (1977) Decrease in postprandial insulin and glucose concentrations by guar and pectin. Ann. Intern. Med. 86, 20-23

6. Junod A., Lambert A. E., Orci L., Pictet R., Gonet A. E. and Renold A. E. (1967) Studies of the diabetogenic action of streptozotocin. Proc. Soc. Exp. Biol. Med. 126, 201-205

7. Kay R. M., Grobin W. and Track N. S. (1981) Diets rich in natural fibre improve carbohydrate tolerance in maturity-onset, non-insulin dependent diabetics. Diabetologia 20, 18-21

8. Mauer S. M., Lee C. S., Najarian J. S. and Brown D. M. (1974) Induction of malignant kidney tumors in rats with streptozotocin. Cancer Res. 34, $158-160$

9. Melnick R. L., Huff J., Haseman J. K., Dieter M. P., Grieshaber C. K., Wyand D. S., Russfield A. B., Murthy A. S. K., Fleischman R. W. and Lilja H. S. (1983) Chronic effects of agar, guar gum, gum arabic, locust-bean gum, or tara gum in F344 rats and $\mathrm{B}_{6} \mathrm{C} 3 \mathrm{~F}_{1}$ mice. Food Chem. Toxicol. 21, 305-311

10. Mizutani T. and Mitsuora T. (1982) Effect of konjac mannan on spontaneous liver tumorigenesis and fecal flora in $\mathrm{C} 3 \mathrm{H} / \mathrm{He}$ male mice. Cancer Lett. 17, 27-32

11. Mizutani T. and Mitsuoka T. (1983) Effect of konjac mannan on 1,2-dimethylhydrazine-induced intestinal carcinogenesis in Fischer 344 rats. Cancer Lett. 19, 1-6

12. Rakieten N., Gordon B. S., Beaty A., Cooney D. A. and Schein P. S. (1976) Modification of renal tumorigenic effect of streptozotocin by nicotinamide: spontaneous reversibility of streptozotocin diabetes. Proc. Soc. Exp. Biol. Med. 151, 356-361

13. Rakieten N., Gordon B. S., Cooney D. A., Davis R. D. and Schein P. S. (1968) Renal tumorigenic action of streptozotocin (NSC-85998) in rats. Cancer Chemother. Rep. 52, 563-567

14. Reddy B. S. (1980) Dietary fibre and colon cancer: Epidemiologic and experimental evidence. Can. Med. Assoc. J. 123, 850-856

15. RoGers A. E. (1979) Nutrition. In The Laboratory Rat Vol. I (ed. BAKER H. J., LINDSEY J. R. and WEISBRoth S. H.) Academic Press, New York, pp. 123152

16. Ross M. H. and Bras G. (1971) Lasting influence of early caloric restriction on prevalence of neoplasms in the rat. J. Nat. Cancer Inst. 47, 1095-1113

17. Tannenbaum A. (1940) The initiation and growth of tumors. Introduction. I. Effects of underfeeding. Amer. J. Cancer 38, 335-350

18. Tannenbaum A. and Silverstone H. (1949) The genesis and growth of tumors. IV. Effects of varying the proportion of protein (casein) in the diet. Cancer Res. 9, 162-173

19. Track N. S., Cannon M. M., Flenniken A., KataMAY S. and Woods E. F. A. (1982) Improved carbohydrate tolerance in fibre-fed rats: Studies of the chronic effect. Can. J. Physiol. Pharmacol. 60, 769776 
20. TuCKER M. J. (1979) The effect of long-term food restriction on tumours in rodents. Int. J. Cancer 23, 803-807
21. Wynder E. L. and Shigematsu T. (1967) Environmental factors of cancer of the colon and rectum. Cancer 20, 1520-1561 